\title{
TRABALHO/EDUCAÇÃO NO PROGRAMA MAIS EDUCAÇÃO: formar para a empregabilidade e para o desemprego
}

\author{
THE RELATIONSHIP WORK/ EDUCATION IN THE PROGRAM MAIS EDUCAÇÃO: \\ training to employability and unemployment
}

TRABAJO / EDUCACIÓN EN PROGRAMA MÁS EDUCACIÓN: form para la empleabilidad y el desempleo

\author{
Magda Cruz dos Santos \\ Doutoranda em Educação pelo Programa de Pós-Graduação \\ em Educação da Universidade Federal de Pelotas (UFPEL). \\ Pelotas - RS, Brasil. \\ magdacs81@yahoo.com.br \\ Conceição Paludo \\ Professora Doutora da Faculdade de Educação da \\ Universidade Federal do Rio Grande do Sul (UFRGS). \\ Porto Alegre - RS, Brasil. \\ c.paludo@terra.com.br
}

RESUMO: O artigo resulta de pesquisa sobre a relação trabalho/educação, no Programa Mais Educação, do Ministério da Educação (MEC - Brasil). Tendo como perspectiva teórico-metodológica o Materialismo Histórico Dialético, analisa os documentos oficiais da política pública investigada. A análise indica que o Programa visa à contenção da violência, à adaptação e conformação das classes trabalhadoras aos efeitos do processo de reestruturação do sistema capitalista, por meio da categoria de Educação Integral. Como central, os resultados da pesquisa expõem a especificidade da relação trabalho/educação que, na estratégia de adaptação e conformação, almeja uma formação voltada tanto para a empregabilidade como para o desemprego.

PALAVRAS-CHAVE: Relação trabalho/educação. Capital e política pública. Programa Mais Educação.

ABSTRACT: The article results from a research about the relationship of work/education, in Mais Educação program, from Ministry of Education (MEC - Brazil). Having as perspective theoretical and methodological the Dialectical and Historical Materialism, it analyses official documents the investigated public policy. The analyses indicate this Program to violence contention, to the adaptation and conformation of working classes to effects of the capitalist system restructuration process, through full-time education category. As central, search results sets it exposes specificity difficulties of work/ education relationship in the strategy of adaptation and conformation, the training both for employability and for unemployment.

KEYWORDS: Relationship work/ education. Capital and public policy. Program Mais Educação.

RESUMEN: El artículo es el resultado de la investigación sobre la relación de trabajo / educación del Programa Más Educación, Ministério de Educación (MEC - Brasil). Desde el punto de vista teórico y metodológico de materialismo histórico dialéctico, análisis los documentos oficiales la política pública investigado. El análisis indica que el programa tiende a la contención de la violencia, la adaptación y la conformación de las clases trabajadoras a los efectos de la reestructuración de sistema capitalista, por categoría de Educación Integral. Como centrales, conjuntos de resultados de búsqueda se expone la especificidad de la relacione trabajo / educación en la estratégia de adaptación y conformación, prevé una formación tanto para el empleo y el desempleo.

PALABRAS CLAVE: Relación de trabajo / educación. El capital y las políticas públicas. Programa Más Educación.

$\overline{\text { Artigo recebido em janeiro de } 2017}$

Aprovado em março de 2017 
TRABALHO/EDUCAÇÃO | Magda Cruz dos Santos e Conceição Paludo

\section{1| INTRODUÇÃO}

No contexto capitalista a relação trabalho/educação constitui um dos eixos centrais na orientação das políticas públicas educacionais. Em cada período histórico, diferentes demandas relativas à formação da classe trabalhadora são incorporadas pela política pública educacional e, neste processo, é possível observar que a relação trabalho/educação assume diferentes direcionamentos (GENTILI, 2012; SAVIANI, 2005).

De modo geral, quando apresenta centralidade na política pública educacional, a categoria trabalho, sob a perspectiva do modo de produção capitalista, assume o sentido de emprego da mão de obra, enquanto que a educação escolarizada assume o papel de qualificação dessa mão de obra - sendo predominantemente manual para os trabalhadores, e intelectual para as classes dominantes e médias, conforme Marx; Engels (1978).

Entretanto, nas últimas décadas observa-se a perda de centralidade da formação técnica para o trabalho, por parte de algumas das políticas públicas educacionais que passaram a ter como foco a necessidade da formação da sociabilidade adequada ao momento atual da sociedade capitalista, a exemplo do Programa Mais Educação do Ministério da Educação (MEC).

Em sua proposta, o Programa constitui uma política direcionada para o Ensino Fundamental e visa implementar a Educação Integral na escola pública, priorizando as populações consideradas em situação de vulnerabilidade social, ou seja, as populações que mais sofrem os efeitos negativos do processo de expansão e acumulação do capital. O Programa, que atingiu ampla expansão pelo território nacional desde seu lançamento em $2007^{1}$, contempla escolas públicas estaduais e municipais atingindo um número expressivo de estudantes. Essas características evidenciam que se trata de um Programa governamental preocupado com a formação dos filhos da classe trabalhadora.

Em pesquisa ao banco de Teses e Dissertações da Comissão de Aperfeiçoamento de Pessoal do Nível Superior (CAPES), encontrou-se um número expressivo de pesquisas que analisam o Programa Mais Educação em diferentes áreas. Foram encontradas quatro teses e sessenta e três dissertações produzidas entre os anos de 2009 e 2015, que apresentaram em seus títulos a expressão 'Programa Mais Educação'. Em sua maioria, as produções apresentam estudos de casos sobre os impactos do Programa em contextos específicos. Para o presente estudo constituiu importante referência à dissertação de mestrado de Félix (2012). Nesta pesquisa, a autora analisa as origens da concepção de Educação Integral do Programa Mais Educação e sua relação com o processo de reprodução do capital. Entre outros resultados, aponta o objetivo do Programa de implementar a 'pedagogia do capital', direcionando a educação pública para os moldes da gestão empresarial e esvaziando de conteúdos de ensino o currículo escolar.

Outras investigações importantes foram a pesquisa de Nóbrega e Silva (2010) e o artigo acadêmico "Conformação e contenção disfarçadas em 'mais educação'", de Elza Peixoto ${ }^{3}$. Ambos os estudos enfatizam que a proposta do Programa Mais Educação visa à adaptação e conformação das classes trabalhadoras aos atuais efeitos do processo de reestruturação capitalista, através da incorporação da categoria de Educação Integral pela política pública.

Diante de um possível recuo dos conteúdos de ensino e da ênfase nas propostas que visam à adaptação e conformação, observou-se a necessidade de investigar a relação trabalho/educação

\footnotetext{
${ }^{1}$ Em oito anos o atendimento do Programa passou de 1,3 mil escolas contempladas para um total aproximado de 60 mil. Disponível em: <http://www.brasil.gov.br>. Acesso em: 10 ago. 2015. Para o ano de 2016, a previsão de cortes para o Programa chegou a 70\%, o que indica a intenção do atual governo em não prosseguir nem com as políticas ditas compensatórias, ou focadas na pobreza. Disponível em: <http://www.esquerdadiario.com.br/Governo-Temeracaba-com-programa-Mais-Educacao>. Acesso em: 15 set. 2016.

${ }^{2}$ Parte dos resultados da investigação realizada pelo grupo GESTOR - Pesquisa em Gestão da Educação e Políticas do Tempo Livre da Universidade Federal de Pernambuco foi encontrada no artigo 'Concepção de Educação Integral no Programa Mais Educação: Analisando valores, diretrizes e objetivos' de Nóbrega e Silva (2010).

${ }^{3}$ Publicado em Boletim Germinal número 9, 2009. Disponível em: <http://www.uel.br/revistas/germinal/n7-052009. $\mathrm{htm}>$. Acesso em: 15 ago. 2014.
} 
presente na proposta do referido Programa, com o objetivo de expor a proposta de formação dos trabalhadores presente nessa política pública e, assim, contribuir com o debate sobre as possibilidades de uma formação humana onilateral, na perspectiva de resistência e superação do modo de produção capitalista.

Considera-se a especificidade da investigação de fundamental importância, uma vez que, ocultando às contradições inerentes ao modo de produção da vida no capitalismo, torna-se mais difícil para a classe trabalhadora consolidar suas alternativas de resistência e organização, em torno de uma educação articulada aos seus interesses, ou seja, uma educação na perspectiva da formação onilateral (MARX; ENGELS, 1978; SOUSA JUNIOR, 2010).

Para o estudo, que teve como perspectiva analítica o Materialismo Histórico Dialético (FRIGOTTO, 2000), utilizou-se o método da Análise Documental (LÜDKE; ANDRÉ, 1986). Ao todo foram lidos 21 documentos acessados no site do MEC. Destes, cinco documentos ${ }^{4}$ foram selecionados para a análise, considerando-se como critérios a abordagem mais direta dos princípios norteadores da categoria de Educação Integral e das orientações para a implementação do Programa que definem as relações de trabalho.

Primeiramente, o artigo, mediante as análises já produzidas (GENTILI, 2012; SAVIANI, 2005; ANTUNES, 2005; SOUSA JUNIOR 2010), contextualiza a relação entre o movimento do capital e as consequentes implicações na política pública educacional. Em seguida, recupera a historicidade do Programa Mais Educação e, na sequência, analisa e explicita a relação trabalho/ educação contida nos documentos de referência do Programa. Por fim, são apresentadas as conclusões da pesquisa.

\section{2 | MUDANÇAS NOS PADRÕES DE ACUMULAÇÃO DO CAPITAL: IMPLICAÇÕES PARA AS POLÍTICAS PÚBLICAS EDUCACIONAIS}

As políticas públicas educacionais constituem uma expressão das profundas transformações que se observa nas últimas décadas. Diante do permanente movimento de reestruturação produtiva e de suas implicações para o mundo do trabalho, as políticas públicas assumem diferentes direcionamentos de acordo com as demandas de cada período histórico. Por isso, a relação trabalho/educação é um eixo fundamental para compreender as contradições de determinada política pública educacional, o que requer análise do movimento do modo de produção capitalista e das demandas que ele impõe para a formação da classe trabalhadora.

No Brasil, as políticas públicas educacionais passaram a assumir uma relevância maior na formação da mão de obra a partir do período de expansão do capitalismo no pós-guerra, devido à ampliação do processo de industrialização e urbanização impulsionado pelo contexto internacional e a ele articulado.

Neste período, da década de 1930 até a crise global do capitalismo na década de 1970, a economia caracterizou-se por uma escala ascendente, na qual a produção em série para o consumo de massa implicou a incorporação de um grande contingente de trabalhadores no mercado de trabalho, impulsionando o desenvolvimento das forças produtivas capitalistas e o avanço tecnológico, motivando o que Gentili (2012) chama de função integradora da educação escolarizada.

\footnotetext{
${ }^{4}$ Os documentos selecionados para análise foram a)Caminhos para elaborar uma proposta de Educação Integral em Jornada Ampliada (BRASIL, 2011a); b)Programa Mais Educação passo a passo (BRASIL, 2011b); c)Rede de saberes Mais Educação: pressupostos para projetos pedagógicos de Educação Integral - Caderno para professores e diretores de escola (BRASIL, 2009c); d)Educação Integral: Texto referência para o debate nacional (BRASIL, 2009a); e e)Programa Mais Educação: gestão intersetorial no território (BRASIL, 2009b).
} 
Entretanto, a partir dos anos 1970 este padrão de acumulação do capital, denominado de taylorismo-fordismo, foi substituído, em escala global, pela acumulação flexível ou toyotismo (SAVIANI, 2005). A denominada acumulação flexível, com o objetivo de ampliar a expansão do capital, gerou uma intensificação da produção em larga escala que, somada ao avanço tecnológico, maximizou a exploração da força de trabalho e ampliou o trabalho precarizado e o número de trabalhadores desempregados, rompendo com o padrão de desenvolvimento anterior. Iniciou-se, assim, um movimento em que o capital passa a prescindir da incorporação de quantidades crescentes de trabalho vivo, criando um contingente humano relativamente desnecessário ao processo de produção e consumo de mercadorias (SOUSA JUNIOR, 2010).

De acordo com Antunes (2005), com o processo de reestruturação produtiva combinou-se o processo de reorganização ideológica e política do capitalismo em escala global. Essas transformações implicaram também em profundas mudanças no papel do Estado e nas políticas públicas educacionais, especialmente pelas novas demandas no que se refere à relação trabalho/educação.

Gentili (2012) destaca que a crise e o redirecionamento do padrão de acumulação capitalista da década de 1970 marcam uma alteração substantiva na função econômica atribuída à escolarização e as políticas públicas educacionais que deslocam a ênfase da formação escolarizada para o emprego, com a progressiva aceitação "[...] do fato de que a educação e o desemprego, a educação e a distribuição regressiva da renda social, a educação e a pobreza podem conviver num vínculo conflitante, porém funcional com o desenvolvimento e a 'modernização' econômica" (GENTILI, 2005, p. 48). A promessa integradora da escola sofre uma desarticulação a partir desse período, o que não supõe a negação da contribuição econômica da escolaridade, e sim uma mudança substantiva de sentido:

\begin{abstract}
Passou-se de uma lógica da integração em função de necessidades e demandas de caráter coletivo (a economia nacional, a competitividade das empresas, a riqueza social, etc.) para uma lógica econômica estritamente privada e guiada pela ênfase nas capacidades e competências que cada pessoa deve adquirir no mercado educacional para atingir uma melhor posição no mercado de trabalho. [...] A desintegração da promessa integradora deixará lugar à difusão de uma nova promessa, agora sim, de caráter estritamente privado: a promessa da empregabilidade. (GENTILLI, 2005, p. 51).
\end{abstract}

Seguindo as orientações dos organismos internacionais, no início dos anos 1990 a produção de políticas educacionais pautou-se pelos objetivos de produtividade, qualidade, competitividade, eficiência e eficácia, articulando transformação produtiva, equidade e conhecimento como elementos centrais para as reformas consideradas urgentes para a América Latina e Caribe.

Reconhecia-se que a complexificação dos processos decorrentes do avanço das forças produtivas e a incorporação de sistemas de manufatura flexíveis haviam transformado a divisão do trabalho e a progressiva desqualificação do trabalhador em entraves à extração de mais-valia. O capital via-se no dilema de elevar a qualificação média dos trabalhadores e, simultaneamente, assegurar o controle sobre eles. Havia, pois, uma situação-limite a ser administrada a qual, entretanto, precisava ser mantida velada. O que estava em causa era o suposto risco de rebelião por parte daqueles que sofrem efeitos deletérios da "modernização conservadora". (EVANGELISTA; SHIROMA, 2006, p. 46).

É assim que, para Evangelista e Shiroma (2006), as políticas educacionais difundiam a ideia de que, para ser cidadão do século XXI e sobreviver à concorrência do mercado, seria preciso dominar os códigos da modernidade.

Sousa Junior (2010) explicita uma contradição dessas políticas ao afirmar que os padrões pro- 
TRABALHO/EDUCAÇÃO | Magda Cruz dos Santos e Conceição Paludo

dutivos e de consumo não se assentam mais na massificação e nem demandam a incorporação crescente de trabalhadores com padrões de qualificação semelhantes. Os novos padrões produtivos e de consumo se assentam no crescimento relativo do capital constante frente ao capital variável e, portanto, no crescimento relativo do trabalho morto em relação ao trabalho vivo. Diante desse quadro,

[...] a realidade da desqualificação é insubestimável. Ela está presente tanto no mundo formal de trabalho - pois nem todas as empresas e ramos produtivos operam com processos produtivos complexos e sofisticados - como é corrente, obviamente, no submundo do trabalho, isto é, no mercado informal, no subemprego, no mundo da precariedade produtiva. [...] A forma como o sistema faz surgir novos instrumentos, tecnologias, cria novos produtos (mercadorias), adota novos métodos de produção e, acima de tudo, cria novas necessidades de consumo, convive com a adoção de velhas práticas ou com a retomada de velhos métodos produtivos cujo objetivo é baratear os custos com a força de trabalho. (SOUSA JUNIOR, 2010, p. 149).

Segundo o mesmo autor, diante da tendência da desindustrialização relativa, no contexto atual coexistem processos produtivos extremamente sofisticados baseados na mais alta tecnologia e que requerem trabalhadores altamente qualificados, e a realidade majoritária da precarização, desqualificação e desregulamentação dos processos produtivos. Portanto, diante da incapacidade de absorver grande parte da massa de trabalhadores nas relações assalariadas formais, a educação passa a se configurar prioritariamente uma das estratégias de controle das classes dominantes, através da formação para uma nova sociabilidade.

\section{I AS ATUAIS DEMANDAS DO SISTEMA CAPITALISTA E AS ORIGENS DO PROGRAMA MAIS EDUCAÇÃO}

Evangelista e Shiroma (2006) afirmam que a partir de meados da década de 1990, houve um redirecionamento nas orientações dos organismos internacionais para as políticas educacionais da América Latina e Caribe, de um viés mais economicista para um viés mais humanitarista. Para as autoras, esse redirecionamento foi uma necessidade decorrente do agravamento das desigualdades sociais causado pelo processo de reestruturação produtiva. Enquanto no início da década de 1990 os documentos de organismos multilaterais, como Banco Mundial e Organização das Nações Unidas para Educação, Ciência e Cultura (UNESCO), ainda destacavam a possibilidade de inclusão da mão de obra e ampliação dos serviços sociais como uma das medidas de contenção da pobreza, no início dos anos 2000 enfatizavam as ideias de oportunidade, autonomia e segurança. "Entendeu-se que o uso intensivo da mão de obra não gerava necessariamente desenvolvimento e que os serviços sociais precisavam ser repensados para além da esfera estatal, envolvendo outros setores sociais" (EVANGELISTA; SHIROMA, 2006, p. 48).

Nesse contexto, a educação escolar passa a ser destacada como um dos elementos para amenização das desigualdades sociais, associando as desigualdades sociais às desigualdades de oportunidades educacionais, como explicitam Falleiros, Pronko e Oliveira (2010, p. 89):

[...] a estratégia de abrandamento da miséria e desenvolvimento econômico se basearia na reestruturação da gestão educacional, na difusão do acesso à educação e na formação da cidadania para o desenvolvimento, mediante acordos entre o Estado, instituições privadas e organismos financiadores externos.

Dessa forma, o objetivo de preparação para o mercado de trabalho, no intuito de garantir a empregabilidade, não se apresenta como central para algumas das políticas públicas educacionais, 
a exemplo do Programa Mais Educação. Destacando que a pobreza precisa ser compreendida não apenas em termos econômicos como também em termos sociais e culturais, surgem as políticas que não pressupõem diretamente a inclusão no mercado de trabalho, mas sim como uma das formas de inclusão social (EVANGELISTA; SHIROMA, 2006).

Assim, segundo Falleiros, Pronko e Oliveira (2010), no lugar da ênfase no conhecimento, na ciência e na tecnologia, observada nas orientações de período anterior, as políticas educacionais passam a enfatizar a formação de uma nova sociabilidade ou nova cidadania, a partir da escola, uma vez que o conhecimento científico- como forma de preparação da mão de obra para o mercado de trabalho - já não se apresenta como necessidade prioritária para a manutenção do sistema capitalista.

É neste contexto que em 2007 é lançado, pelo MEC, o Programa Mais Educação, como uma das propostas do Plano de Desenvolvimento da Educação (PDE), o que explicita uma característica desse Programa: a sua articulação com um projeto de desenvolvimento para o país. $O$ PDE é lançado pelo MEC como um conjunto de ações articuladas para a efetivação do Plano de Aceleração do Crescimento (PAC).

Segundo Leher (2007), o PAC é a materialização nacional das medidas de reorganização do capitalismo em nível mundial, conduzindo à reprimarização dos países subdesenvolvidos de acordo com as novas demandas do capital. O autor afirma que, sob o discurso do crescimento econômico e desenvolvimento social, o Estado nacional encontra o consenso para aplicar as políticas necessárias a esse processo de reorganização do capital, agindo, assim, como fator de agravamento da condição capitalista dependente do país no contexto político e econômico mundial.

Outra característica que se observa nas origens do Programa Mais Educação é que a sua proposição parte de uma das metas do Compromisso Todos Pela Educação, a Educação Integral, que foi incorporada ao PDE.

Saviani (2007) destaca que a referida nomeação, ainda que se apresente como uma iniciativa da sociedade civil, conclamando a participação de todos os setores sociais para a solução dos problemas da educação, constitui-se em uma aliança protagonizada pelos principais grupos empresariais do país, como Grupo Gerdau, Banco Itaú, Banco Bradesco e Organizações Globo, somada à participação de diversas organizações da sociedade civil, sindicalistas, intelectuais e o próprio governo federal. Dessa forma, na análise de Shiroma, Garcia e Campos (2011), o movimento cumpre o duplo papel de vincular-se estreitamente à esfera governamental e assumir um papel de vigilância sobre ela, através dos preceitos de responsabilização e controle social.

Todavia, é possível observar que o Mais Educação não se trata de uma política de caráter estritamente economicista. Isso porque, ao enfatizar o seu direcionamento prioritário para escolas de centros urbanos em situação de vulnerabilidade social, o Programa demonstra estar em consonância com o ideário da Terceira Via, que aponta o controle da pobreza como uma das demandas da política pública. Esse fato lhe confere características peculiares, analisadas adiante. Aqui, cabe destacar a relação estreita da política pública em estudo com o projeto político, social e econômico da Terceira Via (ou social-liberalismo), que no Brasil se expande a partir de meados dos anos 1990, como alternativa para amenizar os efeitos negativos do neoliberalismo (FALLEIROS; PRONKO; OLIVEIRA, 2010).

É nesse sentido que emerge o Programa Mais Educação como uma das estratégias para promover a Educação Integral na escola pública, a partir da Escola de Tempo Integral.

Cabe destacar que a concepção de Educação Integral, atrelada à perspectiva da formação onilateral, constitui uma das categorias centrais nas propostas de educação comprometidas com a emancipação humana. Para Marx e Engels (2004), a formação onilateral representava uma formação integral plena que somente seria possível em uma sociedade emancipada. No entanto, a partir de sua crítica ao modo de produção capitalista e à formação unilateral dos seres humanos 
TRABALHO/EDUCAÇÃO | Magda Cruz dos Santos e Conceição Paludo

nesse sistema, Marx e Engels (2004) destacavam a necessidade de uma Educação Integral que, mesmo sob os limites do sistema capitalista, resgatasse o vínculo entre a formação técnica e a formação intelectual contribuindo para a elevação da classe trabalhadora enquanto classe revolucionária. Essa formação, politécnica, constitui um dos elementos para a superação da sociedade de classes, alcançando a possibilidade de uma formação integral plena, onilateral, em uma sociedade emancipada. A concepção de Educação Integral adotada pelo Programa Mais Educação, difere radicalmente dessa perspectiva, conforme se procurou demonstrar na análise a seguir.

\section{4 | INDICATIVOS DA RELAÇÃO TRABALHO/EDUCAÇÃO EXPRESSA NOS DOCUMENTOS DO PROGRAMA MAIS EDUCAÇÃO}

A análise sobre as origens do Programa Mais Educação corrobora com as pesquisas dos autores de referência e explicita a sua articulação com o projeto de desenvolvimento em curso no país até o ano de 2015, como também com uma das demandas globais do sistema capitalista no período em que o Programa emerge, que é a de educar para a empregabilidade e para o desemprego - a partir da formação para a nova sociabilidade.

A análise dos documentos confirma que uma das principais características dessa política está no seu objetivo de suprir as necessidades sociais e culturais dos sujeitos beneficiados, em detrimento de uma formação que vise suprir ou consolidar conhecimentos científicos trabalhados pela escola e que, mais tarde, possibilitariam o acesso aos níveis mais elevados de ensino e/ou inserção no mercado de trabalho.

Essa característica expressa um novo sentido para a relação trabalho/educação, o que pode ser observado no direcionamento prioritário do Programa à população considerada em situação de vulnerabilidade social, conforme os critérios, divulgados no site do MEC, para a participação das escolas junto ao Programa:

Em 2011, aderiram ao Programa Mais Educação 14.995 escolas com 3.067.644 estudantes a partir dos seguintes critérios: escolas estaduais ou municipais de baixo IDEB que foram contempladas com o PDE/Escola 2009; escolas localizadas em territórios de vulnerabilidade social e escolas situadas em cidades com população igual ou superior a 18.844 habitantes. (BRASIL, 2011c)

O mesmo aspecto está reforçado nos critérios sugeridos para a seleção dos estudantes, já que geralmente o Programa não oferta vagas para todos os estudantes matriculados na escola

\footnotetext{
[...] estudantes que estão em situação de risco e vulnerabilidade social; estudantes que congregam, lideram, incentivam e influenciam positivamente seus colegas; estudantes em defasagem ano escolar/idade;estudantes dos anos finais da 1afase do ensino fundamental (4asérie/5oano) e da $2^{a}$ fase do ensino fundamental (8asérie/9oano), entre os quais há maior saída extemporânea; estudantes de séries/anos nos quais são detectados índices de saída extemporânea e/ou repetência;estudantes que demonstram interesse em estar na escola por mais tempo; estudantes cujas famílias demonstram interesse na ampliação de sua permanência na escola. (BRASIL, 2011b, p. 14, 2011).
}

Segundo Guareschi et al. (2007), o conceito de vulnerabilidade, especialmente nas duas últimas décadas, assume um sentido de insuficiência ou inadequação no acesso às condições de vida e aos suportes sociais que permitam a mobilidade social dos indivíduos dentro das oportunidades oferecidas pela sociedade. Ao criticar esse uso do conceito, os autores afirmam que ele não 
TRABALHO/EDUCAÇÃO | Magda Cruz dos Santos e Conceição Paludo

pode se resumir aos aspectos econômicos, precisando também abranger os aspectos simbólicos que produzem a atual situação.

Abramovay et al. (2002), uma das autoras de referência do Programa, destaca que assumindo que os recursos à disposição do Estado e do mercado são insuficientes para, sozi-nhos, promoverem a superação da vulnerabilidade e de suas consequências, em particular a violência, advoga-se o fortalecimento do capital social intergrupal, através do aumento da participação e valorização das formas de organização e expressão do jovem, como estratégia de ação para envolver a sociedade e seus recursos na busca de soluções para o problema.

A preocupação das políticas públicas fundamentadas nessa perspectiva, entre essas o Programa Mais Educação, está centrada no papel de preparar e adaptar os indivíduos para conviver com as consequências do processo de reestruturação do sistema capitalista e, a partir de suas próprias iniciativas e dos recursos disponíveis, usufruírem das oportunidades que se apresentam para, desse modo, responder melhor às crises e instabilidades do sistema, como se observa no trecho a seguir

Entendemos a relevância da Educação Integral como meio para assegurar o desenvolvimento das crianças e dos adolescentes em todos os âmbitos da condição humana. [...] Para isso, faz-se necessário compreender o processo de trânsito paradigmático que estamos atravessando e que inaugura novas perspectivas de futuro.[...] a Educação Integral constitui ação estratégica para garantir proteção e desenvolvimento integral às crianças e aos adolescentes que vivem na contemporaneidade marcada por intensas transformações: no acesso e na produção de conhecimentos, nas relações sociais entre diferentes gerações e culturas, nas formas de comunicação, na maior exposição aos efeitos das mudanças em nível local, regional e internacional. (BRASIL, 2009b, p. 18, grifo nosso).

O documento referido enfatiza o papel da Educação Integral como meio de adaptação ou preparação das crianças e jovens às transformações sociais em curso, reafirmando-os como sujeitos de direito. Entretanto, conforme se analisou no item anterior, as referidas transformações do mundo contemporâneo resultam do acirramento no processo de expansão e intensificação do modo de produção capitalista, o que implica na crescente redução dos direitos sociais das classes trabalhadoras. Desse modo, ao compreender a Educação Integral como estratégia de 'proteção' e desenvolvimento dos sujeitos para um contexto de transformações, os documentos destacam seu potencial como instrumento de adequação desses sujeitos ao atual contexto do capital e não na consolidação de seus direitos sociais.

Na perspectiva do Programa, a escola poderá cumprir um importante papel como mediadora de um pacto entre Estado, mercado e sociedade civil no sentido de investir no capital social dessas populações. No entanto, nesta política, o conceito de capital social não se apresenta como um elemento a favor da formação humana em sua perspectiva emancipatória. Conforme Abramovay et al. (2002, p. 63-64) ele se refere ao "[...] conjunto de regras, normas, obrigações, reciprocidades e confiança presentes em relações, estruturas e arranjos institucionais da sociedade que permitem seus membros buscar seus objetivos individuais e comunitários." Como se pode analisar, trata-se de uma perspectiva totalmente articulada às necessidades de ajustes na relação entre Estado, mercado e sociedade civil, de modo a garantir os interesses hegemônicos.

Ao longo dos documentos do Programa Mais Educação, ressalta-se a ideia de que a Educação Integral das novas gerações é responsabilidade de todos, sejam governantes ou representantes de outros segmentos sociais, como "empresários, comunicadores, esportistas, juristas, militares, trabalhadores ou de outras profissões" (BRASIL, 2011a, p. 10). Visto que os documentos não definem claramente os limites da relação entre o Estado e a sociedade civil, o que se analisa é a tentativa de produção de consenso entre os diferentes segmentos da sociedade e a possibilidade da intervençào mais direta do capital nas políticas do Estado. 
De acordo com Peroni e Caetano (2012), o Terceiro Setor é o protagonista desse processo, falando em nome da sociedade civil. A chamada Terceira Via propõe reformas por dentro do capita- lismo, ressaltando, portanto, a importância da governança a partir de um pacto entre a sociedade, o mercado e o setor público. A partir dessa configuração, modifica-se a questão social transferindo as responsabilidades do Estado para o indivíduo, impulsionando a disputa pelo fundo público através de uma parceria que, em termos ideológicos, se define como parceria entre Estado e sociedade civil. No entanto, nesse pacto, sociedade civil e Estado são tratados de modo abstrato, desconsiderando os conflitos e as contradições de classe acirradas pelo processo de reestruturação produtiva.

A análise dos documentos explicita que, no caso do Programa Mais Educação, a ênfase na necessidade de trocas culturais entre escola e comunidade, bem como as atividades de proteção social, constituem estratégias de produção de consenso em torno do projeto de educação proposto e, consequentemente, agem no sentido da reprodução da hegemonia. Esse aspecto pode ser observado ao longo dos documentos, que destacam que o distanciamento entre escola e comunidade é cultural e, assim, propõem a intensificação das trocas culturais, também como um mecanismo de aproximação entre Estado e sociedade civil.

Ao se enfrentar a distância que hoje caracteriza as relações entre escola e comunidade é que se pode ampliar a dimensão das experiências educadoras na vida dos estudantes, promovendo a qualificação da educação pública brasileira. Para isso, as diversas experiências comunitárias precisam estar articuladas aos principais desafios enfrentados por estudantes e professores. Quando a escola compartilha a sua responsabilidade pela educação, ela não perde seu papel de protagonista, porque sua ação é necessária e insubstituível, porém não é suficiente para dar conta da tarefa da Educação Integral. Toda escola está situada em uma comunidade com especificidades culturais, saberes, valores, práticas e crenças - o desafio é reconhecer a legitimidade das condições culturais da comunidade para estimular o diálogo constante com outras culturas. (BRASIL, 2009a, p. 34-35).

O objetivo desta aproximação expressa a preocupação com a formação de uma nova sociabilidade, pelo seu potencial para a mudança de valores, atitudes e comportamentos, como também se observa em outro documento (BRASIL, 2011a, p. 26) que enfatiza que a relação entre o currículo escolar e os saberes das comunidades, nas quais as escolas se inserem, pode ainda:

[...] contribuir para mudanças positivas em valores, atitudes e comportamentos. Assim, o desenvolvimento integral dos estudantes não é responsabilidade exclusiva das escolas, mas também de suas comunidades, porque somente juntas podem ressignificar suas práticas e saberes.

A ideia de diálogo entre comunidade e escola é ainda reforçada e articulada com a importância do território na construção de uma identidade coletiva.

As coisas acontecem em um determinado lugar: a escola. Esta, por sua vez, não está num espaço qualquer: ela faz parte de uma comunidade, em um bairro, que se articula com outros para compor uma cidade. A este lugar, onde se encontra a escola, chamamos território, o lugar onde as pessoas vivem e agem. É nesse território que nós estabelecemos laços que definem as relações de trabalho, a convivência com outras pessoas, construímos teias que envolvem elementos simbólicos, de ética, de moral, de comportamento, de cultura, de conceitos estéticos, formando um conjunto que revela o sentido do que significa viver em sociedade. Pertencemos a um território, o guardamos, o habitamos e nos impregnamos dele para realizar-nos como indivíduos, como seres sociais, como coletividade. (BRASIL, 2009a, p. 35). 
Conforme se pode analisar, os documentos enfatizam os aspectos simbólicos e culturais do local e a predominância deles na formação dos indivíduos e nas suas práticas sociais. O "sentido do que significa viver em sociedade", conforme se apresenta nos documentos, parece associado aos laços estabelecidos com outras pessoas do território em que se vive. Nos documentos esses laços aparecem relacionados apenas com os "elementos simbólicos, de ética, de moral, de comportamento, de cultura, de conceitos estéticos" (BRASIL, 2009a, p. 35). Não se encontra referências às condições de produção da vida que fundamentam os modos de ser, sentir e pensar dos sujeitos, conforme demonstraram Marx e Engels (1984, 2009) ao analisar a formação humana sob o modo de produção capitalista. As próprias relações de trabalho aparecem nos documentos como definidas por laços estabelecidos com o local habitado. A relação do território local com o contexto amplo no qual se insere não é ressaltada pelos documentos, transmitindo uma falsa ideia de autonomia das práticas locais e omitindo as relações com um contexto mais amplo que influencia diretamente a configuração do local.

No entanto, apesar da ênfase nos aspectos culturais e simbólicos, em detrimento de uma preocupação mais centrada nas condições materiais do modo de produção da vida desses sujeitos, não é possível afirmar que a relação trabalho/educação não se apresente como um dos eixos principais desta política pública educacional. O que se pode constatar é que esta relação apresenta outro sentido que, fundamentado na ênfase das trocas culturais e da proteção social, constitui-se como um mecanismo de produção de consenso em torno das consequências do processo de reestruturação capitalista - entre estas a impossibilidade do emprego formal para toda mão de obra disponível na atualidade. Dessa forma, também se observa a ênfase que os documentos apresentam no sentido do trabalho como atividade socialmente útil, em contraponto à ideia restrita de trabalho produtivo ou emprego da mão de obra. Esse sentido pode ser percebido quando os documentos destacam a importância do trabalho voluntário, pelo qual se efetivam as atividades do Programa:

Voluntários doam e recebem

[...] O serviço voluntário não gera vínculo empregatício, nem obrigação de natureza trabalhista e previdenciária - mas promove outros vínculos, de natureza pessoal e social, beneficiando não só quem recebe o serviço, mas quem o oferece. (BRASIL, 2011a, p. 45).

Analisa-se que o trabalho voluntário, como definido, é entendido como um mecanismo para fortalecer as relações de solidariedade entre escola e comunidade, o que se traduz na responsabilização da comunidade em funções que deveriam ser garantidas pelo Estado. Além disso, possibilita a ocupação de trabalhadores que se encontram desempregados ou em atividades precárias, promovendo a falsa ideia de valorização de seu trabalho e sem questionar os fatores que geram esta condição.

Cabe ressaltar que, pela perspectiva teórica adotada ao longo desse estudo, a categoria trabalho não se resume ao sentido histórico que assume no modo de produção capitalista, como emprego ou outras formas de trabalho precárias, mas é também compreendida em seu sentido ontológico, o qual Frigotto, Ciavatta e Ramos (2005, p. 4), baseado em Marx e Engels, destaca como

[...] parte fundamental da ontologia do ser social. A aquisição da consciência se dá pelo trabalho, pela ação sobre a natureza. O trabalho, neste sentido, não é emprego, não é apenas uma forma histórica do trabalho em sociedade, ele é a atividade fundamental pela qual o ser humano se humaniza, se cria, se expande em conhecimento, se aperfeiçoa. $O$ trabalho é a base estruturante de um novo tipo de ser, de uma nova concepção de história.

Nessa perspectiva, o trabalho assume sua centralidade como princípio educativo e constitui-se como práxis, tornando o ser humano um ser social (FRIGOTTO, 2009). 
Outro aspecto que se destaca é que a maior parte das atividades ofertadas aos estudantes participantes do Programa não implica a socialização dos conhecimentos científicos, o que deveria ser o principal papel da escola (MARX; ENGELS, 1978). Os documentos indicam que para cumprir a meta de qualificação da Educação Básica, é preciso que a escola além de educadora seja também protetora e, assim, atribuem uma série de funções que até então não faziam parte de sua rotina, como atendimento a saúde, higiene e lazer, entre outras. Ainda que se perceba como fundamental que essas necessidades sejam supridas, é importante considerar que o atendimento dessas demandas através da escola não é a única forma - e nem a mais apropriada -, uma vez que tal opção implica uma alteração significativa no papel da escola pública.

Saviani (1994) alerta para o processo que a escola passa de alargamento de seus encargos, absorvendo uma série de atividades que se acredita terem alguma função educativa, além das atividades extracurriculares. Este processo promove um esvaziamento no papel central que a escola deveria assumir e reproduz-se a contradição de classes que marca o papel da escola na sociedade capitalista (SAVIANI, 1994). Ao não priorizar a socialização do conhecimento, ela "reconstituiu a diferença entre as escolas de elite, destinadas predominantemente à formação intelectual, e as escolas para as massas, que ou se limitam à escolaridade básica ou, na medida em que têm prosseguimento, ficam restritas a determinadas habilitações profissionais" (SAVIANI, 1994, p. 8).

\section{4 | PARA FINALIZAR}

A análise dos documentos do Programa Mais Educação permitiu evidenciar que a relação trabalho/educação, expressa nessa política, não se aproxima da perspectiva "integradora" da escola destacada por Gentili (2012), quando se considerava a possibilidade de pleno emprego, e também não se resume ao sentido da empregabilidade, no que se refere ao investimento na formação qualificada, tendo em vista a disputa no mercado de trabalho. Segundo o que demonstra a análise, o objetivo da política em estudo é a formação de uma nova sociabilidade, no sentido de minimizar as conseqüências do processo de reestruturação capitalista, entre estas a violência e o desemprego.

A especificidade da investigação realizada traz, como importante, a qualificação dessa nova sociabilidade no que diz respeito à relação trabalho/educação. Essa nova sociabilidade se apresenta, conforme a análise, assentada na formação dos trabalhadores tanto para a empregabilidade como para o desemprego, sendo essa uma das estratégias de adaptação e conformação dos trabalhadores às necessidades atuais do capital.

Além disso, as análises demonstram que essa política flexibiliza o papel da escola no que diz respeito ao conhecimento e ao incorporar uma das categorias centrais dos projetos de educação na perspectiva da emancipação humana, a Educação Integral, apresenta limites para a organização das classes trabalhadoras como protagonistas de seu projeto de escola e, sobretudo, para a explicitação das contradições que envolvem o processo de reestruturação capitalista.

Entretanto, ao evidenciar as contradições que envolvem a proposição da política pública em estudo, e considerando a crise vivida na atualidade no Brasil, não se pressupõe a impossibilidade da apropriação do Programa pelas classes populares como mecanismo de resistência. No entanto, reforça-se a necessidade de sua articulação com outro projeto de sociedade, pelo qual seja possível a superação das contradições entre capital e trabalho e uma educação na perspectiva da formação onilateral.

Com base na análise apresentada, procurou-se apontar os indicativos que permitem expor a relação trabalho/educação presente na proposta do Programa Mais Educação, conforme se sintetizou nas considerações finais do artigo. 
TRABALHO/EDUCAÇÃO | Magda Cruz dos Santos e Conceição Paludo

\section{Referências}

ABRAMOVAY, M. et. al. Juventude, violência e vulnerabilidade social na América Latina: desafios para políticas públicas. Brasília, DF: UNESCO, 2002.

ANTUNES, R. O caracol e sua concha: ensaios sobre a nova morfologia do trabalho. São Paulo: Boitempo, 2005.

BRASIL. Ministério da Educação. Secretaria de Educação Básica. Caminhos para elaborar uma proposta de educação integral em jornada ampliada. Brasília, DF: MEC; SEB, 2011a. (Série Mais Educação).

Ministério da Educação. Secretaria de Educação Básica. Programa mais educação passo a passo. Brasília: MEC; SEB, 2011b.

Ministério da Educação. Secretaria de Educação Básica. Secretarias e escolas: mais educação. Brasília, DF: MEC, SEB, 2011c. Disponível em: <http:// portal.mec.gov.br/programa-mais-educacao/secretarias-e-escolas>. Acesso em: 5 ago. 2013.

Ministério da Educação. Secretaria de Educação Continuada, Alfabetização e Diversidade. Educação integral: texto referência para o debate nacional. Brasília, DF: MEC; SECAD, 2009a. (Série Mais Educação).

Ministério da Educação. Secretaria de Educação Continuada, Alfabetização e Diversidade. Programa mais educação: gestão intersetorial no território. Brasília, DF: MEC; SECAD, 2009b. (Série Mais Educação).

Ministério da Educação. Secretaria de Educação Continuada, Alfabetização e Diversidade. Rede de saberes mais educação: pressupostos para projetos pedagógicos de educação integral: caderno para professores e diretores de escola. Brasília, DF: MEC; SECAD, 2009c. (Série Mais Educação).

EVANGELISTA, O.; SHIROMA, E. O. Educação para o alívio da pobreza: novo tópico para a agenda global. Revista de Educação, Campinas, n. 20, p. 43-54, jun. 2006.

FALLEIROS, I.; PRONKO, M. A.; OLIVEIRA, T. C. de. Fundamentos históricos da formação/atuação dos intelectuais da nova pedagogia da hegemonia. In: NEVES, L. M. W. (Org.). A direita para o social e a esquerda para o capital: intelectuais da nova pedagogia no Brasil. São Paulo: Xamã, 2010.

FÉLIX, M. I. F. O Programa Mais Educação no contexto de crise estrutural do capital: um estudo à luz da centralidade ontológica do trabalho. 2012. 119 f. Dissertação (Mestrado em Educação) - Universidade Federal do Ceará, Fortaleza, 2012.
FRIGOTTO, G. Escola e trabalho numa perspectiva histórica: contradições e controvérsias. Revista de Ciências da Educação, n. 9, mai./ago. 2009.

O enfoque da dialética materialista histórica na pesquisa educacional. In: FAZENDA, I. (Org.). Metodologia da pesquisa educacional. São Paulo: Cortez, 2000. p. 71-90.

FRIGOTTO, G.; CIAVATTA, M.; RAMOS, M. O trabalho como princípio educativo no projeto de educação integral de trabalhadores. In: COSTA, H. da; CONCEIÇÃO, M. Educação integral e sistema de reconhecimento e certificação educacional e profissional. São Paulo: Secretaria Nacional de Formação - CUT, 2005. p. 63-71.

GENTILI, P. Educar para o desemprego: a desintegração da promessa integradora. In: FRIGOTTO, G. (Org.). Educação e crise do trabalho. Petrópolis: Vozes, 2012.

Três teses sobre a relação trabalho a educação em tempos neoliberais. In: SAVIANI, D. (Org.). Capitalismo, trabalho e educação. Campinas: Autores Associadas; Histedbr, 2005.

GUARESCHI, N. M. F. et al. Intervenção na condição de vulnerabilidade social: um estudo sobre a produção de sentidos com adolescentes do programa do trabalho educativo. Estudos e Pesquisas em Psicologia, Rio de Janeiro, v. 7, n. 1, p. 20-30, abr. 2007.

LEHER, R. Programa de aceleração do crescimento a heteronomia cultural. Revista de Políticas Públicas, v. 1, p. 9-102, 2007.

LÜDKE, M.; ANDRÉ, M. E. D. A. Pesquisa em educação: abordagens qualitativas. SãoPaulo: EPU, 1986.

MARX, K.; ENGELS, F. A ideologia alemã: teses sobre Feuerbach. São Paulo: Ed. Moraes, 1984.

Crítica da educação e do ensino: introdução, tradução e notas de Roger Dangeville. Paris: Maspero, 1978.

Manifesto do partido comunista: crítica ao programa de Gotha. Tradução Sueli Tomazini Barros Cassal. Porto Alegre: L\&PM, 2009.

Textos sobre educação e ensino. Tradução Rubens Eduardo Frias. São Paulo: Centauro, 2004.

NÓBREGA, S. A.; SILVA, J. A. A. Concepção de educação integral no programa mais educação: analisando valores, diretrizes e objetivos. In: JORNADA DE INICIAÇÃO CIENTÍFICA: JOAQUIM NABUCO E A LUTA PELA CIDADANIA, 14., 2010, Recife. Anais... Recife: FACEPE, 2010. 
TRABALHO/EDUCAÇÃO | Magda Cruz dos Santos e Conceição Paludo

PEIXOTO, E. Conformação e contenção disfarçadas em 'mais educação'. Boletim Germinal, n. 9, nov. 2009.

PERONI, V. M.; CAETANO, M. R. Redefinições no papel do estado: terceira via, novo desenvolvimentismo e as parcerias público-privadas na educação. Revista FAEE$B A$, v. 21, p. 57-67, 2012.

SAVIANI, D. (Org.). Capitalismo, trabalho e educação. Campinas: Autores Associadas; Histedbr, 2005.

O plano de desenvolvimento da educação: análise do projeto do MEC. Educação e Sociedade, Campinas, v. 28, n. 100 - Especial, p. 1231-1255, out. 2007.
. O trabalho como princípio educativo frente às novas tecnologias. In: FERRETI, C. J. et al. (Org.). Novas tecnologias, trabalho e educação: um debate multidisciplinar. Petrópolis: Vozes, 1994.

SHIROMA, E. O.; GARCIA, R. M. C.; CAMPOS, R. F. Conversão das "almas" pela liturgia da palavra: uma análise do discurso do movimento todos pela educação. In: BALL, S. J.; MAINARDES, J. (Org.). Políticas educacionais: questões e dilemas. São Paulo: Cortez, 2011.

SOUSA JUNIOR, J. de. Marx e a crítica da educação: da expansão liberal-democrática à crise regressivo-destrutiva do capital. Aparecida: Ideias \& Letras, 2010. 